\title{
Use of Family Narratives as a Tool of Effective Parenting
}

\author{
Rakesh Kumar Maurya $^{1}$ *
}

\section{ABSTRACT}

Family narratives and reminisces can be effectively used by parents as a tool to help children develop self-concept. Family narratives are the way through which children and adolescents connect across generations to create self- identity. By anchoring oneself in family history, one develops a sense of place and security that may facilitate self-confidence and self-competence. In the modern world where nuclear family is the norm, parents need to ensure that family narratives are used effectively in helping children navigate through challenges of life. Parents and grandparents have to pay careful attention to family history and narratives; and put in efforts in developing strong family narratives to be shared with children. Also, parents need to be careful while sharing those reminisces and narratives by avoiding individual comparison of their children with others in the past. Celebrating certain occasions as a day for showing gratitude towards grandparents and older generations can also generate curiosity and interest among children about family narratives. The current study looks into family narratives practices, challenges and how parents can develop strong family narratives to be shared with their children.

Keywords: Parenting, Family Narratives, Family Stories, Story, Reminisces, Effective Parenting,

We make stories and our stories make us(McAdams, 1993; Wingard \& Lester, 2001; Plummer, 2002; Gottschall, 2012). All societies across the world have used this powerful tool not only to entertain their people but also to transfer cultural values from one generation to another. Humans in all cultures come to cast their own identity in some sort of narrative form (Owen Flanagan, 1992).

Like its culture, India has rich traditions of storytelling: Katha, Mask, Puppets, Pandwani, Kathkali, picture showmen etc. are some of the most popular traditions of storytelling. The content of these traditional stories are from religious texts such as Ramayana, Mahabharata, Purans etc. These story telling performances are held in temples, weddings and other social or religious functions. However, apart from these traditions, there is another tradition of

\footnotetext{
${ }^{1}$ Shiv Savitri Mahavidyalaya Faizabad

*Responding Author

(C) 2016 I R Maurya; licensee IJIP. This is an Open Access Research distributed under the terms of the Creative Commons Attribution License (http://creativecommons.org/licenses/by/2.0), which permits unrestricted use, distribution, and reproduction in any Medium, provided the original work is properly cited.
} 
storytelling: Story telling by older generation to the younger one in families. This tradition was very popular and probably the most widely practiced. Grandparents/parents are the main story tellers of this tradition and children are the main audiences of it. The content of these family stories are from the same religious text and animal stories for children. Panchtantra (Five Principles) is one of the most popular children stories narrated to children. This is "an ancient Indian collection of interrelated animal fables in verse and prose, arranged within a frame story. The original Sanskrit work, which some scholars believe was composed around the 3rd century BCE" (Jacob, 1888; Ryder, 1925) is attributed to Vishnu Sharma. This work has been translated into many languages and has migrated to different parts of the world since then (Buchthal, 1941; Upadhyaya, 1960; Saxena, 1999).

Stories shared and communicated in families can be categorized as: Family stories and Nonfamily stories. Family stories content is derived from past events and experiences of family members dead or alive. It consists of family history, traditions and reminisces of past generations and current members. Family stories includes both stories of experiences the family has shared together in the remote past, such as family vacations and sibling births, as well as stories outside of the children's experience, including stories of the parents before the children were born, both as children in their own families of origin and as adults before forming this family (Fivush, Bohanek\& Duke, 2007).Non-family stories are stories related to religious or cultural texts and are not related to family history.

My grandfather's reminisces about his hard life during his childhood and the change of his fortune after he fled to Kolkata in search of employment had a profound influence on me as a child. All his personal stories started with some challenges or hardships in the family such as how hard it was to manage three meals a day or how his father worked on others land as a labourer; and ended with courageously fighting with those challenges. I developed a deep respect for my grandmother who died a few months before my birth, when I heard from others about her gracious and kind hearted nature in helping the poor. A rickshaw-puller from a neighboring village once told me about a loan he took from her but she never asked for the return; and when he tried to return the money after her death, my grandfather forfeited the load saying that she would be happy by this act.

Family stories such as mentioned above when told and retold become a part of family narratives and play an important role in shaping personality and self of family members (Stone, 1988). Family stories have many functions. One of the prime functions of family stories is to convert family experiences/memories into a forever long lasting story. In his book, The Things They Carried, O'Brien says

"And sometimes remembering will lead to a story, which makes it forever. That's what stories are for. Stories are for joining the past to the future. Stories are for those late hours in the night when you can't remember how you got from where you were to where you are. Stories are for 
eternity, when memory is erased, when there is nothing to remember except the story (O'Brien, 1998, p. 38).

Telling a story is a key tool to find meaning in that particular experience (Boyce, 1996; Koenig Kellas \& Trees, 2006). A personal experience/remembrance when told and retold takes the form of a story which makes it more meaningful both for the narrator as well as the listener. Also, family stories integrate other family members' experiences making it more meaningful for the whole family. Another function of family narratives is to organize family experiences into meaningful content and use that knowledge to better prepare for future challenges. In fact, they work as a bridge between the past and the future.

Family stories are a key tool for transmitting values, experiences, traditions and important life lessons to current or future generations (Fiese \& Wamboldt, 2003).

The current study argues for (A) why it is important for families to create strong family narratives to be shared with children? (B) How nuclear family system has influenced the sharing and communication of family narratives? (C) How strong family narratives can be used as an effective tool of parenting? (D) How parents can create strong family narratives to be shared with their children? The word "Family Narrative" and "Family Story" have been used interchangeably in this paper; and convey the same meaning.

\section{Family Stories Vs Non-family stories:}

Story telling is one of the oldest art forms and they are everywhere coming from all walks of life. The domain of these stories is such a vast world that it is difficult to categorise them. On the basis of relation between characters and story teller, it can be divided in two categories: family stories and Non-family stories. Family stories are tales about people, places, and events related to the members of our immediate family or ancestors. Non-family stories can be defined as tales about people, places and events which are not related to members of our immediate family or their ancestors.

While all types of stories leave their impact on narrator as well as listeners, family stories are more influential in identity formation as compared to non-family stories. They tell them where they came from, where they fit into the historical landscape of the entire family, what are the values that family has been practicing over the years, how family has dealt with challenges over generations etc. It helps children in developing strong intergenerational self (Fivush, Bohanek \& Duke, 2008). Family stories are about the family members and history of the family. Therefore, when strong family narratives are shared with the younger generation, it sets an example or a standard for children to meet or exceed.

Family reminisces and narratives are perceived to be based on real events which took place in past or a few generations ago while non-family stories we read/hear are not necessarily perceived to be based on real events. When a preadolescent or an adolescent hears or reads a story, he/she 
takes it as a fictional story whereas family narratives are perceived to have happened in the past and based on real life events. This is why family narratives directly leave an impact on children as compared to other stories.

Another difference is the level of connection children feel with the characters of a family story and non-family story. A family narrative would evoke a strong feeling of connection with the characters as they are part of a larger family while non-family stories may evoke a feeling of strong connection but not as much as family narratives.

Family reminisces and narratives carry many real life connections in the form of objects, materials and signatures of events. For example, a grand-father, retired from Army, may narrate stories of wars he fought and can show the wounds/scars on his body received during the war; a grand-mother while narrating her first meeting with her husband to her grand-children can show the gift he gave to her.

Family stories are better suited to be used as a cohesive force in keeping the family united while other stories may not necessarily have this feature (Kiser, Baumgardner \& Dorado, 2010).Family stories and reminisces are a key factor in developing a strong intergenerational self which is closely related to more trust worthy relations among current family members (Fivush, Bohanek \& Duke, 2008).People having low intergenerational self may be more prone to discard other family members in their old age. In today's world, where old people taking shelter in old age homes despite having children has become a reality, family stories are vital in influencing younger generation in taking care of their parents in their old age. Indian immigrants living in United States use home based, family focused simple narratives to inform their children about their roots in India. As these immigrants are living away from their extended families, family narratives and stories are a way to incorporate them in their family in United States (Marvin2009).

\section{Impact of Family Narratives on Children:}

Family narratives influence children in a variety of ways. It impacts the emotional life of a family and its members (Fivush, Bohanek, Robertson \& Duke, 2004). A five year old when expresses her past experiences about a particular event to her parents develops autobiographical and self-memory; and observes how her experiences about the past are different from others experiences of the same event (Fivush, 2008).Understanding of Self emerges from social interactions and it also influences social interactions.

Family stories does not only influence the listener i.e. children but narrator as well. How we share our experiences with others shapes our own understanding of those experiences (Fivush, Reese, \& Haden, 1996; Pasupathi, 2001). Through describing, explaining, and evaluating their pasts in socially situated reminiscing, children come to construct an interpretive framework for understanding both their experiences and their selves (Fivush, Bohanek\& Duke, 2007). 


\section{Use of Family Narratives as a Tool of Effective Parenting}

Family stories provide a historical context for children, informing them of how they fit into a larger life framework. Family narratives are the way through which children and adolescents connect across generations and create self- identity. The whole process of sharing of family history and stories helps children develop a sense of self connected to previous generations. By anchoring oneself in family history, children develop a sense of place and security that may facilitate self-confidence and self-competence (Fivush, Bohanek \& Duke, 2007).

Sharing of family narratives with children contributes in the development of strong intergenerational self which in turn help children develop a better sense of self and well-being. Sharing of Family narratives is an important contributor in the preadolescents' well-being and self-understanding (Fivush, Bohanek \& Duke, 2007). As children approach adolescence, development of intergenerational self may also works as a resilience factor.

Family narratives promote family cohesiveness which plays a key role in creating strong family bonding among family members and children in particular. Family cohesion is defined as the "emotional bonding that family members have toward one another" (Olson, Russell, and Sprengkle, 1984). These narratives also strengthen the adaptability of families in response to situational and developmental stress.Family narratives, when told and retold, define the shape of each family's emotional life. The way individual family members take part in the recreation of family's shared past regulates an evolving self-understanding both as an individual and as a member of the family. Families that are skilful in talking about emotionally complex and difficult events in more open, integrated, and coherent ways may help impart children with the resources to deal with and resolve aversive experiences (Fivush, Bohanek, Robertson \& Duke, 2004).

\section{Why sharing of family narratives and story-telling is decreasing among Parents?}

During a workshop on parenting, the author observed that there are many parents particularly from low SES who avoid sharing family stories/histories with their children. In fact, they try their best to keep their children away from their ancestral places and people, thinking that this would pollute the mind of their children. They argue, "what to share?, our past has not been that eventful, it is full of shame, sorrow and exploitation." This reluctance is very obvious with the parents of low castes in India who have migrated to cities in search of better opportunities.

They fear that if they expose their children to their extended families who are still backward, poor and living in villages, it would hamper their social and academic development. They also fear that their children's mingling with their extended families in villages would hamper their growth as they do not have anything to offer except unhealthy old rituals and traditions. History of Schedule castes and Schedule Tribes and other lower caste people in India is a history of thousands of years of servitude, exploitation and oppression on the basis of being born in a particular community or caste (Maurya; 2015). While social and economic conditions of

backward castes have improved significantly in modern India, revisiting those past traumatic 
experiences in the form of family narratives would, they fear, hurt their children's self-esteem. The issue can be summarised as they feel "lack of strong family narratives" to be shared with their children.

The word "grandparents" evokes a unique world where the dual role of parenting is evinced. Grandparents function as shock absorbers, which buffer the aftershocks and they also act as bouncing boards, which help to deflect a range of emotions. These roles serve to emphasize their important link in the family. With a plethora of old world experiences behind them, and having the unique capacity of being able to transmute from mentors and listeners to mediators and friends, they can offer support and stability.In a traditional joint family, grandparents play a crucial role of transmitting family values, traditions and lessons to children through family narratives. In India, this has been the tradition in families, however, in the changing family structures where nuclear family has become the norm, this crucial role of grandparents in sharing family narratives to children has now been neglected. As more people are migrating from villages to cities, they find themselves being cut off from their roots (Saxena, 1977).

Technology is another crucial aspect of changing family dynamics. Impact of popular culture and technology is very much visible on children's relationships in families.(Taylor, 2013).These influences have contributed to a growing divide between the traditional roles that children and their parents play. Children's absorption in technology, from texting to playing video games, does by their very nature limit their availability to communicate with their parents. Children's absorption in technology, from texting to playing video games, has limited their communication with parents and grand-parents. One study observed that working parents arrived home after work were greeted only $30 \%$ of the time and were ignored $50 \%$ of the time. Another study found that there was no impact on family time when technology was used for school related activities, but it hurt family communication when used for social reasons. Children these days are found indulging in instant messaging constantly, checking their social media, listening to music, surfing their favorite web sites, and watching television or movies. Because of the emergence of smart phones, these exercises are no longer limited to the home, but rather can occur in cars, at restaurants, public places, in fact, anywhere there's mobile phone network coverage.

These new development have impacted sharing of family narratives with children. It is not that only children are responsible for decrease in family communication. Parents can be equally responsible for widening the distance that appears to be increasing in families. Often, they are busy with their own technology, for instance, watching TV, checking emails and talking on their mobile phones, when they could be playing with, talking to, or generally connecting with their children.

Another factor responsible for the decrease or lack of sharing of family narratives with children is parents not being aware of the importance and benefits of such family practices. This could be 
overcome by school counsellors who are competent enough to help parents learn the importance of family narratives and how it should be communicated (Maurya, 2015). The author himself, as a school counsellor, conducted workshops on effective parenting to spread awareness for the same.

\section{How to Develop Strong Family Narratives?}

Simply sharing family narratives with children is not enough. It is important to develop and share strong family narratives which can assist children in developing a positive self-concept, enhanced resilience and well-being in response to emotional or social challenges. As we have already discussed about parents who feel that they do not have anything positive to share with their children, it is imperative to understand how one can develop strong family narratives to be shared with their children.

First, the assumption that family narratives should be $100 \%$ historically accurate is misguided; in fact, no historical event can claim to be of hundred percent accurate. When any historical event is interpreted, it is coloured by narrator's own biases, interpretation and understanding. Stories when transferred from one generation to the next, some changes are bound to happen as memory is of constructive nature (McClelland, 1995; Schacter, Norman \& Koutstaal, 1998). It means that the act of remembering is influenced by various other cognitive processes including perception, imagination and beliefs (Johnson \& Raye, 2000). During retrieval of past family events people use their schematic knowledge to fill in information gaps, though they usually do so in a way that implements aspects of their own beliefs, moral values, and personal perspective that leads the reproduced memory to be a biased interpretation of the actual version. It means that parents have the flexibility of accommodating interpretations of past history of their family that they deem conducive for the development of their children. 


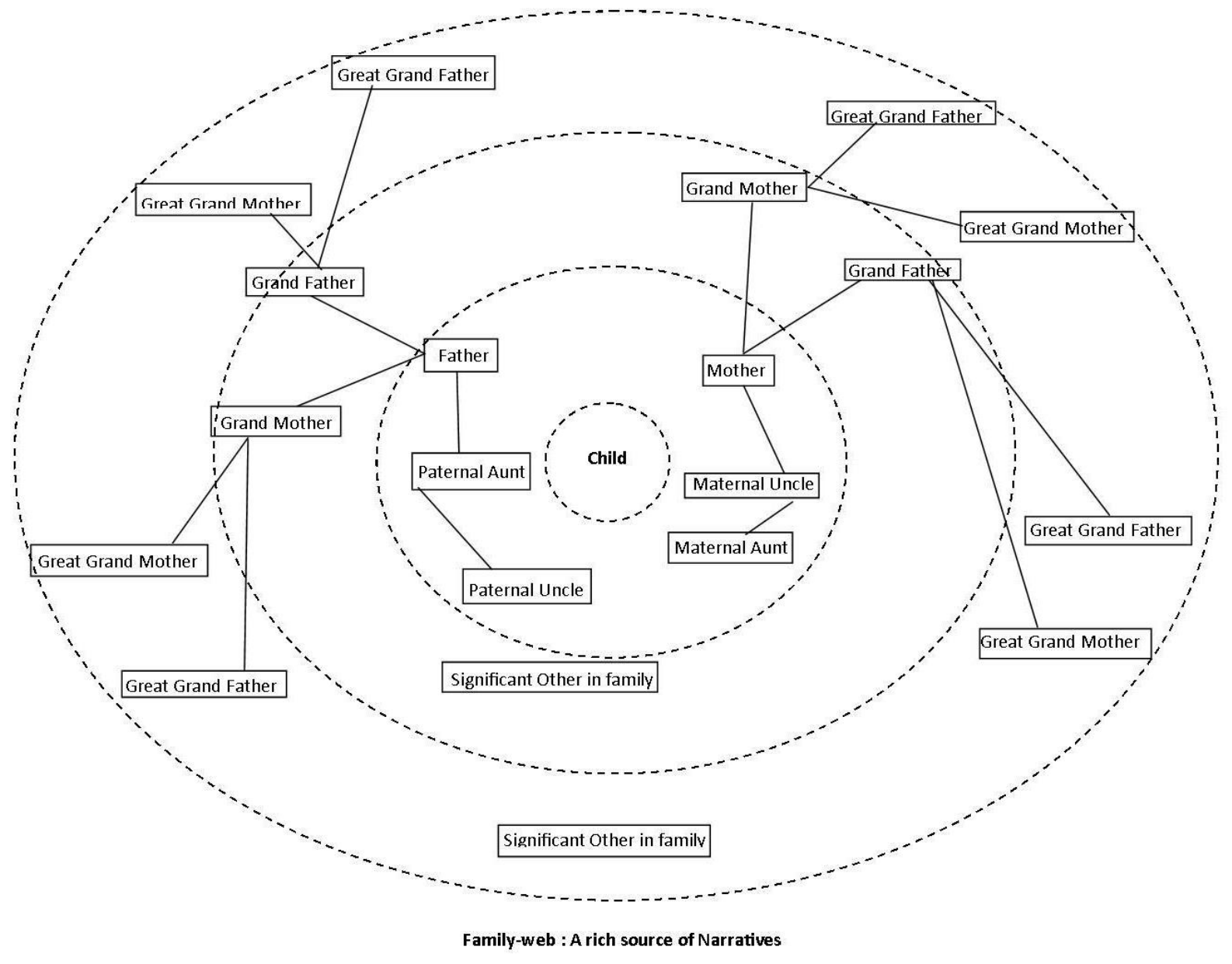

The author proposes the following steps for parents in developing strong family narratives.

Step 1- The first step is to understand the values of the family. Family values are important and lasting beliefs or ideals shared by the members of a family about what is good or bad and desirable or undesirable.Every family practises certain values. These values are transferred from generation to generation and changes are also adopted with social, economic and political atmosphere of the time (Becvar \& Becvar, 2012).For parents it is important to first understand what these values are. The following questions can help parents understand values of their families.

- What is important to you?

- What is important to your family?

- How your family is same or different to other?

- What is the purpose and goal of your family?

- History of your family?

- What defines happiness, pride and fulfillment for the members of your family?

- What are the values of other family members? 
The above mentioned questions are not absolute and other strategies may be adopted to understand values of a family. Once family values are deciphered, core family values should be developed through brain storming among family members.

Step 2- Second step is to be aware and have appropriate understanding of family history .If parents themselves are not aware of their family history and narratives, it would be difficult for them to transfer those narratives to their children. For understanding their own family history, they need to do their own research and collect data for the same. Family-web (see figure-1) can help in discovering family history, narratives and values.

Another approach to generate family narratives is to study family history along with the history of your community/caste, village/town, district, state and country. A family history can not remain isolated from what happened in society at the time.

Step3- The third step is look at the family history and narratives from the lens of core family values. The past narratives become more meaningful and inspiring when filtered and coated with family values.

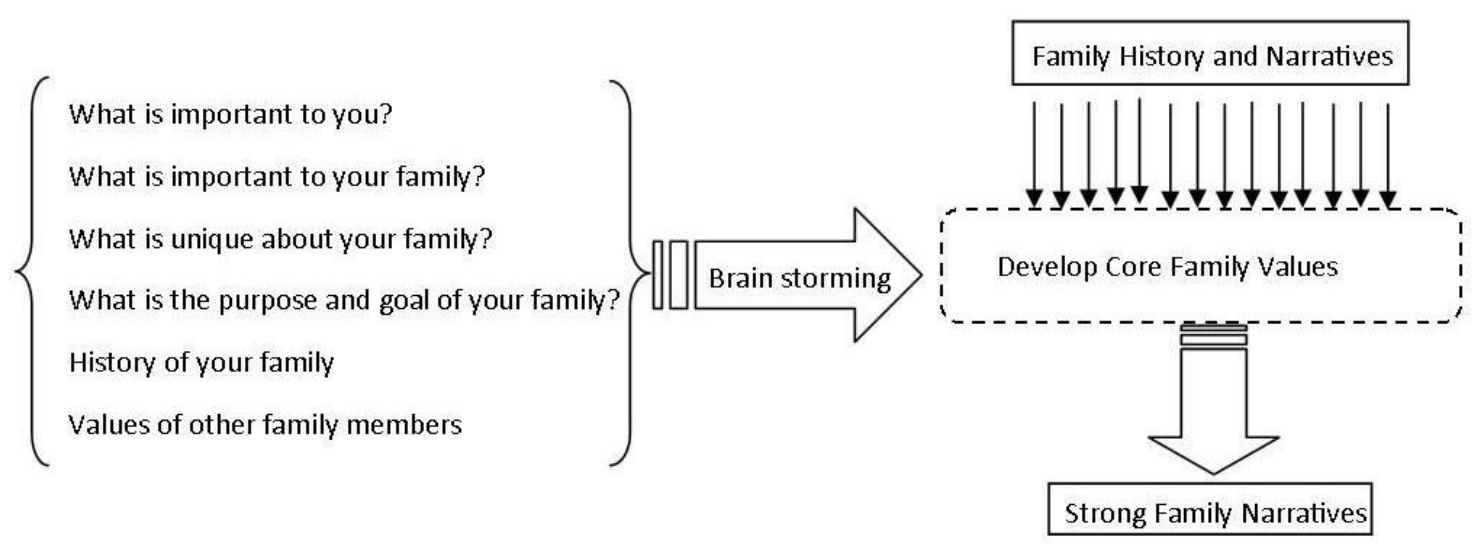

It is important for parents to develop strong family narratives to be shared with children

\section{Sharing Family Narratives with Children}

One does not need to be an effective story teller to share family narratives with one's children, however, parents having effective story narration skills would find themselves better equipped in turning family history into a coherent and engaging plot. Sharing family narratives should not be based on oral traditions only. Environmental cues that support narratives or at least work as a link or remains of the past family history are more effective when shared. A family photograph is not only a picture of an individual/group or a scene, in fact; it carries its own story. It is 


\section{Use of Family Narratives as a Tool of Effective Parenting}

commonly believed that a photograph is worth a thousand words (Bouch, 2009; McGee \& McGee, 2011).Family photographs are one of the most common and effective environmental cues that can generate curiosity and interest among children about family narratives and history. Having photographs of elders or earlier generation is commonly done and families in some cultures even worship them along with their Gods (Hozumi, 1912; Sheils, 1975; Lee, 1987).

Apart from photographs, old items such as medals, coins, dresses, and gifts can also evoke emotional bonding with the previous generation and help develop strong intergenerational self among children. These things effectively help parents in transferring/communicating family values among children. Children find it easy to connect with family narratives and history when they themselves touch, feel and observe such objects.

Another way of sharing family narratives is to celebrate certain occasions as a day for showing gratitude towards grandparents and older generations. In India, there is a cultural tradition of celebrating an event for showing respect and gratitude to our dead parents, grandparents and ancestors. This is known as "Shradh". Shradh is a sanskrit word and it literally means "Anything done with complete faith and devotion". On this occasion, a period of fifteen lunar days which is observed every year during PitraPaksha, Hindus pay homage to their ancestors especially though food offerings. Such cultural celebrations are the appropriate time for sharing family narratives and history. The ritual performed during Shradh can generate curiosity as well as gratitude towards deceased family members.

Another problem that parents face while sharing family narratives is that children do not show interest in those narratives. Parents assume that the past historical family events and stories are of no use/interest for their children. My grandfather almost always used to reminisces about how he travelled 6 kilometers on foot to go to school. He reminisced these narratives whenever I insisted for purchasing a bicycle for myself. Another usual reminisces of my grandparents was when I showed tantrums about the food. "You should feel happy that you are getting three meals a day, in our time, we used to get to eat only two times and that too only rice and vegetables." These narratives were always repeated whenever I showed dissatisfaction with the food served, and after some years, I became used to these didactic narratives. Therefore, it is important for parents to understand how and when such narrative should be shared. First, a family narrative with a sarcastic tone would certainly not create the influence that we want to see on our children. Parents often used comparative and sarcastic tone while sharing family narratives. For example:

"How come you ask for a new pair of shoes when you already have one, in your age I used to go to school barefoot?"

Second, timing of sharing family narratives matters. Rather than reacting to an incident instantly, it is better to relate that with past family narratives when you are with your child in a deep intimate conversation. In the example mentioned above, parents can reminisce about the 
challenge of not having even a single pair of footwear at night after dinner while striking a deeper level of child-parent communication.

Third, the manner in which a parent/grand-parent used family history to make a point also matters. Children avoid listening to something conveyed in a didactic manner. For example:

"Children should respect elders, in your age we did not even look into the eyes of our elders while talking to them."

This didactic approach can be made more effective if we change the didactic style of reminisces. "It hurts when someone younger to you does not show respect to you. I realised this when I was of your age, how do you feel when someone does not show respect towards you?"

Fourth, early exposure of family narratives to children is more effective as compared to late exposure. Preadolescence when children start forming their identity and self is an ideal time for exposing children to family history and narratives (Bohanek, Marin, Fivush\& Duke, 2006).

\section{CONCLUSION}

Family narratives can be effectively used by parents as a tool to help children develop selfconcept. Family narratives are the way through which children and adolescents connect across generations to create self- identity. By anchoring oneself in family history, one develops a sense of place and security that may facilitate self-confidence and self-competence. In the modern world where nuclear family is the norm, parents need to ensure that family narratives are used effectively in helping children navigate through challenges of life. Parents and grandparents have to pay careful attention to family history and narratives; and put in efforts in developing strong family narratives to be shared with children. Also, parents need to be careful while sharing those reminisces and narratives by avoiding individual comparison of their children with others in the past. Celebrating certain occasions as a day for showing gratitude towards grandparents and older generations can also generate curiosity and interest among children about family narratives.

\section{REFERENCES}

Becvar, D. S., \&Becvar, R. J. (2012). Family therapy: A systemic integration. Pearson Higher Ed.

Bohanek, J. G., Marin, K. A., Fivush, R., \& Duke, M. P. (2006).Family narrative interaction and children's sense of self.Family process, 45(1), 39-54.

Bouch, J. (2009). A picture is worth a thousand words. Advances in psychiatric treatment, 15 (2), 81-81.

Boyce, M. E. (1996). Organizational story and storytelling: a critical review. Journal of organizational change management, 9(5), 5-26.

Buchthal, H. (1941). Indian fables in Islamic art. Journal of the Royal Asiatic Society of Great Britain \& Ireland (New Series), 73(04), 317-324. 
Fivush, R. (2008). Remembering and reminiscing: How individual lives are constructed in family narratives. Memory Studies, 1(1), 49-58

Fivush, R., Bohanek, J. G., \& Duke, M. (2008). The intergenerational self: Subjective perspective and family history. Self continuity: Individual and collective perspectives, 131-143.

Fivush, R., Bohanek, J., Robertson, R., \& Duke, M. (2004).Family Narratives and the Development of Children's Emotional Well-Being.

Gottschall, J. (2012). The storytelling animal: How stories make us human. Houghton Mifflin Harcourt.

Hozumi, N. (1912). Ancestor-worship and Japanese law. Maruzen Kabushiki-Kaisha.

Johnson, M. K., \&Raye, C. L. (2000).Cognitive and brain mechanisms of false memories and beliefs.Memory, brain, and belief, 35-86.

Kiser, L. J., Baumgardner, B., \& Dorado, J. (2010). Who are we, but for the stories we tell: Family stories and healing. Psychological Trauma: Theory, Research, Practice, and Policy, 2(3), 243.

Koenig Kellas, J., \& Trees, A. R. (2006). Finding meaning in difficult family experiences: Sense-making and interaction processes during joint family storytelling. The Journal of Family Communication, 6(1), 49-76.

Lee, K. K. (1987). Ancestor worship and kinship structure in Korea. Religion and ritual in Korean society, 56-70.

MaRSHaLL, D. U. K. E. (2008). The Intergenerational Self Subjective Perspective and Family History. Self Continuity: Individual and Collective Perspectives

Marvin, Lee-Ellen.(2004). Why Mamiji Cried: Telling Stories and Defining Families. Storytelling, Self, Society.Vol. 1, Iss. 1

Maurya, R.K. (2015). Advocacy Counseling in India: Current Scenario and the Road Ahead. Asian Academic Research Journal of Humanities and Social Sciences (AARJSH) Vol. 2(6), 233-254.

Maurya, R.K. (2015). Effective Parenting: A Master Key. Humanities and Social Science Studies (HSSS) Vol.4 (1), 23-28.

Maurya, R.K.(2015). Do Hindi Cinema \& Television Serials Propagate Caste Stereotypes

Maurya, R.K.,Singh, S. (2015). Traumatic Childhood Experiences and Stuttering: A Case Study. Asian Academic Research Journal of Humanities and Social Sciences(AARJSH) Vol.2(6), 331-351.

McAdams, D. P. (1993). The stories we live by: Personal myths and the making of the self. Guilford Press.

McClelland, J. L. (1995). Constructive memory and memory distortions: A parallel-distributed processing approach. Memory Distortion: how minds, brains, and societies reconstruct the past, 69-90

McGee, R. G., \& McGee, L. M. (2011). A picture is worth a thousand words. American Journal of Transplantation, 11(4), 871-872.

Nigrelli, C. Keeping Families Strong-Part Two Positive Communication. 
Plummer, K. (2002).Telling sexual stories: Power, change and social worlds. Routledge.

Saxena, D. P. (1977). Rururban migration in India: causes and consequences. Popular Prakashan. Saxena, I. (1999). Indian children's stories through the centuries. Bookbird, 37(2), 56.

Schacter, D. L., Norman, K. A., \& Koutstaal, W. (1998). The cognitive neuroscience of constructive memory. Annual review of psychology, 49(1), 289-318.

Sheils, D. (1975). Toward A Unified Theory of Ancestor Worship A Cross-Cultural Study. Social Forces, 54(2), 427-440.

Stone, E. (1988). Black sheep and kissing cousins: How our family stories shape us. Transaction Publishers.

Tayler, Jim.(2013) Is Technology Creating a Family Divide. Retrieved on January 14, 2016 from https://www.psychologytoday.com/blog/the-power-prime/201303/is-technologycreating-family-divide

Through Surnames of Characters: A Content Analysis? Economic and Political Weekly.(In press).

Upadhyaya, K. D. (1960). A General Survey of Indian Folk Tales.Midwest Folklore, 181-196.

Wingard, B., \& Lester, J. (2001).Telling our stories in ways that make us stronger. Adelaide, Australia: Dulwich Centre Publications. 